\title{
Shooting with a Camera
}

\author{
By DOUG GILROY, Regina
}

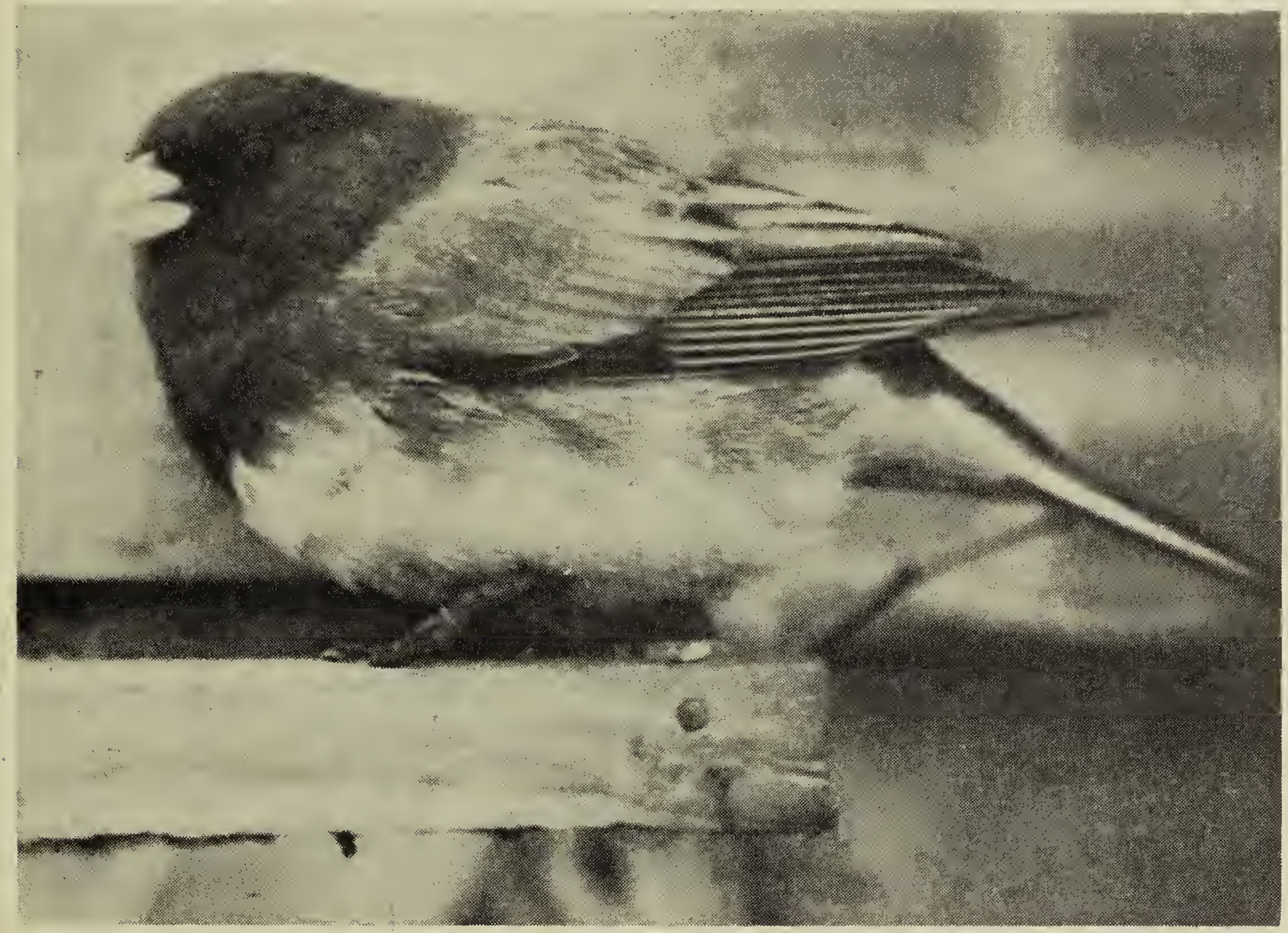

To me shooting wildlife with a camera is just as exciting and thrilling as hunting wild game with a gun. There is never a closed season and it is a sport anyone can be successful at if they will just persevere. As with gun shooting there will be hits and misses.

There are many different methods used to shoot birds and animals with a camera. Some will use telephone lens, others will use different types of remote control units to set off their cameras, or perhaps shoot from blinds or then again all of these methods maybe combined.

How was the picture of the Slate Colored Junco taken? It is plain to see the bird is perching on some kind of a shelf and in the background there is a suggestion of a brick wall. Where was the photographer when the picture was taken? "Why", says someone, "where else could he be but right in front of the bird where he could plainly see it. You can see the Junco is looking right at him." Well, my friend you are wrong. The bird was photographed outside by a wall allright but I was comfortably seated in the house on the chesterfield, and to the opposite side to the bird you see in the picture. In fact all I could see of the bird by glancing out of the window was its tail sticking out from the side of the feed box.

The box is a self-feeder and was filled with bird seed. This was hung on a stick about 15" above the ground and in a sheltered spot alongside of the house. The Juncos buzzed around this free lunch like a bunch of bees after honey. The camera was placed on a short tripod about a foot away from the feeder shelf and focused on the spot I thought the Junco would alight on. A portrait lens was placed over the regular lens and the remote control unit connected to the camera. Next the cable was strung through the living room window to the chesterfield. I might add the feeder had to face the opposite way from the house so as to be illuminated properly by the sun.

In a jiffy the birds were back and I knew by the protruding tail at the feed box that a bird was there, but I was not sure if the bird was absolutely motionless or if it were in a good pose. The tail became very steady and hoping the rest of the bird was likewise clicked the shutter. That shot was a success, the next was a blurr. 